\title{
Analysis of Development of Internet of Things Technology and Training of Professional Talents
}

\author{
Yiran Liu ${ }^{1, a}$ \\ ${ }^{1}$ Beijing University of Posts and Telecommunications,China, \\ a3026261552@qq.com
}

Keywords: Internet of Things, Technical foundation, Internet of Things works, Professional training Abstract: This paper describes the definition and technical basis of Internet of Things, and explores the generation and development of Internet of Things, then introduces the impact of the Internet of Things, including the impact on individuals, cities, and even the country. The author slso analyzes the professional training plan of Internet of Things from the perspective of the students of Internet of Things, and studies the overall goals, curriculum, knowledge and skills and training direction.

\section{Overview of internet of things}

Internet of Things is seen as a wave of information industry after the computer, Internet and mobile communication network. It will have a great impact on the world economy, politics, culture, military and other aspects. It will be the high point of a new round of competition in the information industry ${ }^{[1]}$. Its final direction will certainly point to the achievement of 'information society'. In this goal, information technology will become the main wealth of society and information will become the main driving force for development and intelligence will become a new power dispute. It could be said that who masters more information resources, who will have more advantages in the fields of politic, economy, science and technology, especially information war $^{[2]}$.

\section{Basic concept of Internet of Things}

Internet of Things is a network that can connect every items, achieve intelligent Identify, locate, track, monitor and manage, according to an agreement, through the radio frequency identification (RFID), infrared sensors, GPS, laser scanners and other information sensing equipment ${ }^{[3-4]}$. Internet of Things is 'the Internet connect things with things'. There are two meanings, on the one hand, the core and foundation of the Internet of Things is still the Internet and the extension and expansion of the Internet on the basis of the network. On the other hand, the user was extend into items to exchange of information and communication.

\section{The Generation and Development of Internet of Things}

\section{Situation abroad}

(1) The idea of the Internet of Things can be traced back to Bill Gates's The Way to the Future in1995.

In this book, Bill Gates has mentioned the concept of interconnection of objects, but was limited by the wireless network, hardware and sensor equipment development, so it haven't been taken seriously.

(2) In 1998, the Massachusetts Institute of Technology (MIT) creatively presented the idea of the Internet of Things, which was called the EPC system.

(3) In 1999, based on the items code, RFID technology and the Internet, the United States Auto-ID 
Center first proposed the concept of Internet of things.

(4) On 17 November 2005, at the World Summit on the Information Society (WSIS), the International Telecommunication Union (ITU) issued the ITU Internet Report 2005- Internet of Things. The report pointed out that the ubiquitous 'Internet of Things' communication era is approaching, all objects in the word from the tire to the toothbrush, from the house to the paper towels can exchange information through the Internet automatically.

(5)In 2008, the European Intelligent Systems Integration Technology Platform (EPoSS) reported in the Internet of Things in 2020 predicts that the development of the Internet of Things in the future.

(6) After Obama became the president of the United States, on January 28, 2009 with the US industrial and commercial leaders held a 'round table conference'. As one of two representatives, IBM CEO Peng Mingsheng for the first time proposed the concept 'wisdom of the earth', proposed new government to contribute a new generation of intelligent infrastructure. Obama has responded positively: "Funds for economic stimulus will be put into the emerging technology of broadband networks, no doubt that this is the way that United States to maintain and regain the competitive advantages in the 21 st century.

(7)In 2009, the Executive Committee of the European Union published Internet of Things - An action plan for Europe, which depicts the prospects of the application of Internet of Things. And proposed to strengthen the management of the Internet of Things, improve privacy and personal Data protection, improve the credibility of the Internet of Things, promote standardization, the establishment of an open environment for innovation, promote the application of Internet of Things and other action proposals.

(8)The Korea Communications Commission promulgated the Basic Planning for Infrastructure Infrastructure Development in 2009, which was based on a series of RFID / USN (sensor network) programs made by Korean government previously. The goal is to build the world's most advanced Internet of things infrastructure, the development of Internet of things services, research and development of Internet of things technology, to create a network of things to promote the environment after RFID / USN application and experimental network.

(9)In 2009, the Japanese government IT strategy headquarters developed a new generation of information technology in Japan, 'i-Japan Strategy 2015', the strategy aims to make digital information technology as air and water into every corner till 2015. It is focusing on e-government, health care and education professionals, activating industry and geographical activity and nurturing new industries, and reorganizing digital infrastructure.

\section{Situation inside}

Our government also attaches great importance to the research and development of Internet of Things. On August 7, 2009, Premier of the State Council Wen Jiabao delivered an important speech during the inspection in Wuxi, and put forward the strategic conception of "sensing China", saying that China should seize the opportunity and vigorously develop the Internet of Things technology.

On November 3, 2009, Premier Wen Jiabao delivered a speech Let science and technology lead China's sustainable development to the capital science and technology sector. Once again stressed that it is very important to scientifically choose new strategic industries and instructed to break 
through the sensor network, and the key of Internet of Things technology.

In January 19, 2010, Wu Bangguo, chairman of the Standing Committee of the National People's Congress, visited Wuxi Institute of Internet of Things Industry, said to nurture the development of Internet of things and other emerging industries, to ensure that China can get an invincible position in a new round of international economic competition. A series of important speeches, reports and relevant policies and measures at the top of the government have shown that the development of the Internet of Things industry will become an important strategic decision in the future.

\section{Technical foundation}

Internet of things is a multi-domain technology with a cross of the new information technology, the four major technical bases are radio frequency identification technology, sensor technology, object embedded intelligent technology, miniaturization technology and nanotechnology ${ }^{[5]}$.

\section{Changes brought by the Internet of things}

The impact of the ubiquitous Internet of Things on the world is enormous, from individual to urban and national construction.

\section{The influence of Internet of Things on personal life}

Everything in the world, no matter a small button or a large cars, aircraft, if add a micro-chip into those and make them intelligent, so it can achieve the exchange of information with people and things, which is the Internet of Things. Out of the house in hot summer, the owner can open the home air conditioning through the phone in advance. Cars entry and exit the housing estate with intelligent registration, navigation with the GPS, paste smart labels to items on the surface or inside, then it can get its location by software, etc. These Internet of Things technology provide a great convenience for people.

\section{The impact of Internet of Things on cities and countries}

The birth of the Internet to reduce the earth into a village, make people linked more closely. On the basis of the Internet of Things technology, people can manage production more precisely and convenient, and achieve the goal 'wisdom of the Earth'.

\section{Smart city}

The impact of Internet of Things on urban management is mainly reflected in the unified monitoring of urban security and the digital management of the city. Unified monitoring of urban security based on the broadband Internet real-time remote monitoring, transmission, storage, management of the business. Make the scattered, independent image collection point into network by the use of broadband and $3 \mathrm{G}$ networks. To achieve unified monitoring of urban security, unified storage and unified management, for the city management and builders to provide a new, intuitive, visual range extended management tools.

\section{Smart transportation system}

Including the bus industry wireless video surveillance platform, intelligent bus platform, electronic ticketing, car expert and bus phone card five business. Greatly increased the speed of people's travel, not only to improve the country's traffic level, but also greatly improve the efficiency of the country's work.

\section{The cultivation of students of the Internet of Things works}

\section{Overall objective}

Students of the Internet of Things should have a good mathematical and physical basis and 
should master the relevant theory and application design method of the Internet of Things, also they should have the strong ability of computer technology and electronic information technology, and master the literature retrieval, data query the basic method. They need to have the ability to successfully read the professional foreign language information, with listening, speaking, reading and writing ability ${ }^{[6]}$.

\section{Curriculum}

Students of the Internet of Things Engineering are required to master these courses.

(1)Basic courses: the theory of signal and system, networking technology, digital circuit and logic design, communication principle I, JAVA high-level language programming, electronic system foundation, etc.

(2) Major courses: artificial intelligence principle, data warehouse and data mining, multimedia technology, data structure, database, control theory, radio frequency identification (RFID), self-organizing network and broadband wireless communication, wireless sensor network, Internet of things information processing technology, operating system, Internet of Things engineering practice, cloud computing, middleware technology, microprocessor system design, communication principles II, mobile Internet, information network theory,etc.

\section{Knowledge and skills}

The knowledge and skills which the students need to master include: (1) Master and computer science and technology related to the basic theoretical knowledge.(2) Master the Internet of things analysis and design of the basic methods. (3) Master the literature search, data query the basic method, Have the ability to obtain information .4) To understand the laws and regulations related to things. (5) able to use learning knowledge and foreign language reading ability to access foreign language information.

\section{Talent development}

Things related to the diversity and complexity of disciplines in China, some experts believe that it is 'discipline' rather than 'professional', is not trained out of professional talents. Especially undergraduate stage, most likely to learn but not fine, it is recommended in the graduate stage and then its further study, so that it is possible to cultivate a real fine professionals. The research direction of Internet of Things is mainly focused on: Internet science and technology, computer science and technology, electronics and communications engineering, and so on.

\section{Conclusion}

Internet of Things as a symbol of the information revolution again, will bring mankind into a new era of "Smart Planet" to achieve the true meaning of all interconnection, interconnection of objects, people interconnected, so that people more deeply feel the nature of matter and changes, to promote a deeper level of communication around the world. The value of science and technology and business which Internet of Things brought about are immeasurable, and in the information war, the Internet of Things will play a great role. In the current, countries try to seize the commanding heights of this technology through the development of science and technology, personnel training 
and other ways.

\section{References}

[1] Sheng Kuixiang. On the Development and Application of Internet of Things Technology [DB/OL]. http://www.cnki.net.2010.

[2] Zhang Kangyi. Application of Internet of Tings in Military[J]. Intelligent Processing and Application, 2012(1):66-69.

[3] Wu Minghu. On the Opportunity and Challenge of the Introduction of Internet of Things [J]. Information Technology, 2010(5):23-27.

[4] Fan Xuemei. A Survey on Development of Internet of Things[J]. Computer Measurement and Control ,2011,19(5):1002-1004.

[5] Sun Qibo, Liu Jie, Fan Chunxiao. Internet of Things: Summarize on Concepts ,Architecture and Key Technology Problem [J]. Journal of Beijing University of Posts and Telecommunications,2010,33(3):2-10.

[6] Wu Yigong. Reflections on the Construction of Teaching System of Internet of Things Engineering [J]. Computer Education,2010,10(21):26-29. 